\title{
Does methylprednisolone affect time to recovery in COVID-19 pneumonia?
}

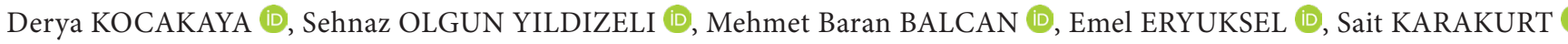

Department of Pulmonary and Critical Care Medicine, School of Medicine, Marmara University, Istanbul, Turkey.

Corresponding Author: Derya KOCAKAYA

E-mail: drderyagun@gmail.com

Submitted: 16.01.2021 Accepted: 28.03.2021

\begin{abstract}
Objective: Current literature has conflicting results on the role of steroids in the treatment of coronavirus disease 2019 (COVID-19) pneumonia. This study aims to evaluate the effects of steroids on clinical recovery, duration of hospitalization, and time needed for the cessation of oxygen treatment.

Patients and Methods: We retrospectively analyzed the medical records of patients hospitalized for COVID-19 between March and May 2020. Patient age, laboratory parameters, clinical stages, radiologic scores, length of hospital stay, and time needed for the cessation of oxygen supplementation were compared.

Results: Thirteen patients were treated with steroids, and 12 controls were included in the analysis. Regarding the laboratory parameters, the groups were similar except for lymphocyte percentage $(9.8 \pm 3.2,7.0 \pm 2.9 ; \mathrm{p}=0.033)$, which was higher, and $\mathrm{D}$-dimer levels (0.75 (0.60-1.43), 1.57 (0.91-2.29); $\mathrm{p}=0.047)$, which were lower in the steroid group on admission. Steroid treatment provided a tendency of decrease in time to cessation of oxygen supplementation $(6.23 \pm 3.4$ vs $7.67 \pm 2.1, \mathrm{p}=0.217)$.

Conclusion: Although, systemic steroids, started in the subacute period, did not affect the length of hospital stay, they provided a tendency of decrease in the time until the cessation of oxygen supplementation in the subacute period.

Keywords: COVID-19, Steroids, Length of stay
\end{abstract}

\section{INTRODUCTION}

The new type of coronavirus, which appeared in Wuhan, the capital of China's Hubei region in December 2019, spread in a short time and caused a worldwide pandemic $[1,2]$. The new type of coronavirus, named as severe acute respiratory syndrome coronavirus type 2 (SARS-CoV-2), and the disease it causes, coronavirus disease-19 (COVID-19), mainly targets the lower respiratory tract [2]. Although, the infection is mild in $81 \%$ of cases, it may result in respiratory failure, septic shock, and multi-organ failure in $5 \%$. The fatality rate of the disease has been reported as $2.1 \%$ [3].

In the course of disease in advanced stages, distal airway involvement may result in alveolar destruction. It has been demonstrated that this lung damage is associated both with the virus and an uncontrolled immune response and an alveolar injury similar to acute respiratory distress syndrome (ARDS) [4]. On the other hand, the fact that lung compliance is preserved in some cases with hypoxemic respiratory failure suggests that there are other possible mechanisms in the development of hypoxemia other than alveolar damage [5]. In particular, it has been suggested that uncontrolled excessive inflammation tends to increase coagulation and can cause both arterial and venous thromboembolic disease. Also, the detection of pulmonary microthrombi in autopsy series supports the view of another possible cause for hypoxemia in these cases $[1,6]$. The presence of hypoxemia in patients or prolonged hypoxemia is associated with prolonged hospitalization.

How to cite this article: Kocakaya D, Olgun Yildizeli S, Balcan MB,Eryuksel E, Karakurt S. Does methylprednisolone affect time to recovery in COVID - 19 pneumonia? Marmara Med J 2021; 34(2):120-126. doi: 10.5472/marumj.942800 
Although, the use of anti-malarial agents in combination with anti-viral and macrolide antibiotics is recommended in the early treatment of the disease, the use of biologic agents may be an option in the event of an excessive inflammatory response in patients whose viral replication phase is over [7]. Corticosteroids are widely used in severe community-acquired pneumonia, especially in suppressing excessive and dysfunctional systemic inflammation [8]. Although, there are contradictory results about the use of systemic steroids in non-COVID viral infections in general, the idea that pulse-dose therapy and long-term highdose steroid use is associated with more harm than benefit due to increased viral replication and the adverse effects of steroids [9-11]. However, it has been shown that corticosteroid therapies (usually 200-300 mg/day hydrocortisone, for 5-7 days) given at the correct dose and time in selected patient groups may have some clinical benefits and prevent pathologic deterioration [12, 13]. At the beginning of the pandemic, the use of steroids is very limited in SARS-CoV-2 infection. Wei et al. reported clinical improvement in patients who received an average of $400 \mathrm{mg} /$ day hydrocortisone equivalent steroid treatment for an average of 9.5 days [14]. In July 2020, the preliminary data of the Randomised Evaluation of COVID-19 Therapy (RECOVERY) trial showed that especially patients with respiratory failure have decreased 28-day mortality in the dexamethasone treatment [15].

Hence, we retrospectively analyzed the medical records of 13 patients treated with steroids because of ongoing oxygen need and 12 control patients with a similar clinical picture to evaluate the effect of steroid treatment on clinical recovery, duration of hospitalization, and the time to the disappearance of oxygen need in patients with COVID-19.

\section{PATIENTS and METHODS}

\section{Patients}

The study was conducted at Marmara University, School of Medicine Pulmonary and Critical Care Medicine Clinic. The permission was obtained from the Ministry of Health of the Republic of Turkey on May $10^{\text {th }}, 2020$, and ethical approval was obtained from the Marmara University, School of Medicine Clinical Research Ethics Committee (approval number: 09.2020.561).

The data of patients who were hospitalized with COVID-19 pneumonia between March $13^{\text {th }}, 2020$, and May $25^{\text {th }}, 2020$, with severe acute respiratory infection (SARI) criteria (fever, cough, and dyspnea, tachypnea, hypoxemia, hypotension, widespread radiologic findings, and confusion) and found to have positive polymerase chain reaction (PCR) test results in oropharyngeal - nasopharyngeal swab samples were retrospectively examined. Among them, patients who still require oxygen supplementation despite standard medical treatment (anti-malarial, anti-viral, and macrolide antibiotics as single or combination regimen), in which other causes of secondary hypoxemia were clinically excluded, were analyzed. None of the patients were on long-term oxygen treatment before COVID-19 pneumonia for a known chronic respiratory illness. Thirteen patients treated with steroids and 12 patients with similar clinical pictures but who were not treated with steroids were included in the final analysis (Figure 1).

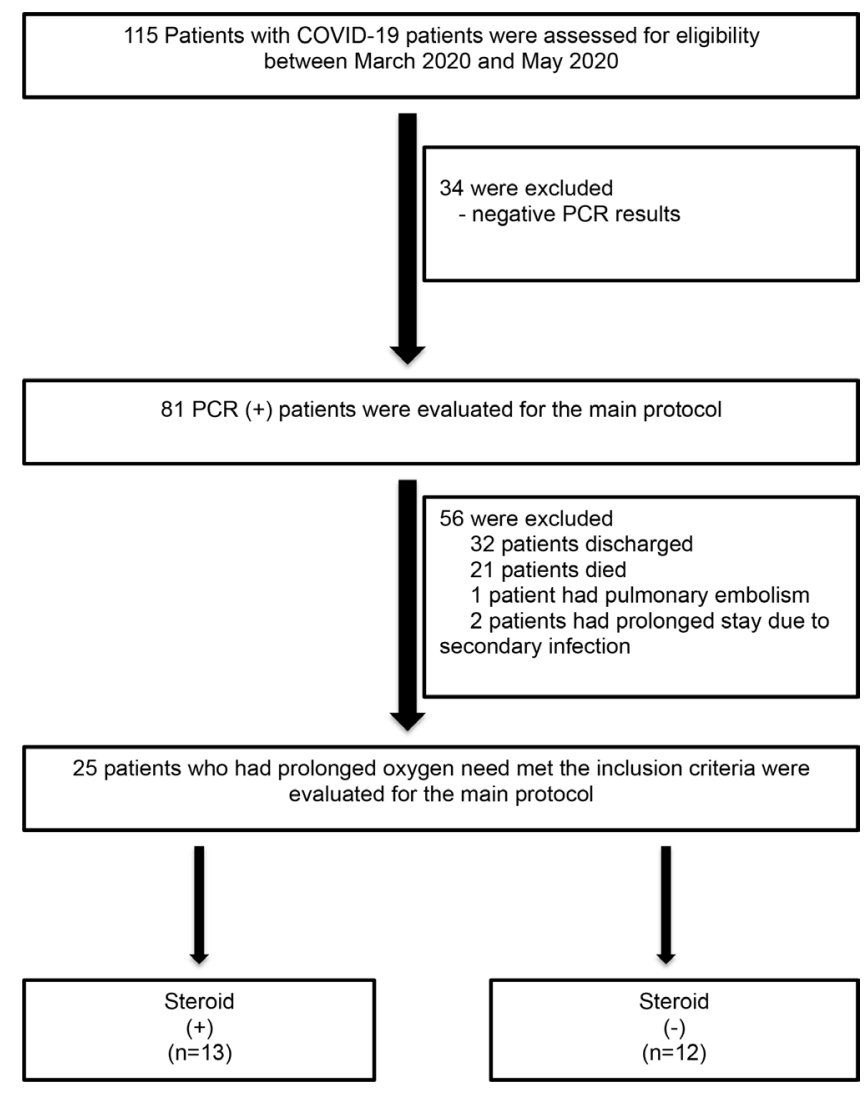

Figure 1. Flow diagram of the study

\section{Demographics and comorbidities}

All patients' gender, age, comorbid diseases (hypertension, diabetes mellitus, hyperlipidemia, chronic lung disease, coronary artery disease, congestive heart failure, thyroid dysfunction, chronic liver disease), smoking status, positive case contact history, the time between the onset of the first symptom, and the hospital admission were recorded.

\section{Standard treatment}

The treatments that patients received during their hospital stay were evaluated daily by three experts (pulmonary and critical care physicians) and treatment modifications were made according to the daily physical examinations and laboratory findings. Treatment planning for COVID-19 was implemented following the guideline prepared by the Republic of Turkey, Ministry of Health [16].

The recommended treatment scheme in this guide is hydroxychloroquine $200 \mathrm{mg}$ bid maintenance after $400 \mathrm{mg}$ bid loading for a total of 7-10 days [in patients with normal QT distance in electrocardiography (ECG) taken at the time of hospitalization] +/ - azithromycin $250 \mathrm{mg} /$ day after $500 \mathrm{mg} /$ day loading for 5 days (optimal), and additional favipiravir 600 
mg bid after $1600 \mathrm{mg}$ bid loading in patients with high oxygen demand and respiratory distress for a total of 5 days. All patients were treated with low-molecular-weight heparin (LMWH) according to $\mathrm{D}$-dimer levels at the time of hospitalization (D-dimer levels $<3 \mathrm{mg} / \mathrm{L}$ were treated with $0.01 \mathrm{mg} / \mathrm{kg} /$ day once daily, D-dimer levels $\geq 3 \mathrm{mg} / \mathrm{L}$ were treated with $0.02 \mathrm{mg} / \mathrm{kg} /$ day bid).

\section{Laboratory parameters}

In all cases, complete blood count (lymphocyte \%, lymphocyte count $\left.\times 10^{3} / \mu \mathrm{L}\right)$ D-dimer $(\mathrm{mg} / \mathrm{L})$, NT-proBNP (N terminalproBrain Natriuretic Peptide) (ng/L), C-reactive protein (CRP) $(\mathrm{mg} / \mathrm{L})$, procalcitonin $(\mu \mathrm{g} / \mathrm{L})$, ferritin $(\mu \mathrm{g} / \mathrm{L})$, fibrinogen $(\mathrm{mg} /$ $\mathrm{dL})$, lactate dehydrogenase $(\mathrm{LDH})(\mathrm{U} / \mathrm{L})$ results at admission and during hospital stay were recorded. In addition to the laboratory values on admission; the lowest values for lymphocyte percent, lymphocyte count, and fibrinogen level; the highest values for CRP, D-dimer, NT-proBNP, procalcitonin, ferritin, and LDH during hospitalization were included in the statistical analysis.

\section{Severity of disease}

Clinical staging for all patients during hospitalization was calculated based on the values on admission and worst clinical picture, according to the World Health Organization (WHO) progression scale [17] and the clinical-therapeutic staging suggested by Siddiqi et al. [18]. On the 7th-10th days, due to the continuation of the need for oxygen, re-staging was performed. Radiologic severity was assessed using computed tomography (CT) visual quantitative evaluation from 0-20 [19]. Each lung lobe was assessed for the percentage of lobar involvement and classified as none (0\%), minimal (1-25\%), mild (26-50\%), moderate $(51-75 \%)$, or severe (76-100\%), with a corresponded score as $0,1,2,3$, or 4 . The total severity score was reached by summing the five lobe scores.

\section{Steroid treatment}

The patients who still needed oxygen therapy on days 7-10 were evaluated for other possible causes of hypoxemia. H-scores were calculated for patients who were not considered as having clinical hypervolemia or pulmonary embolism or secondary bacterial infection [20] because of the risk of macrophage activation syndrome (MAS). In patients with H-scores <169, according to the opinion of the pulmonary medicine specialist in the clinic, single-dose intravenous methylprednisolone $0.5-1$ $\mathrm{mg} / \mathrm{kg} /$ day was started and tapered according to the need for oxygen in 7-10 days.

\section{Statistical Analysis}

Data are shown as mean \pm standard deviation (SD), median and interquartile range (IQR), 95\% confidence interval (CI), and categorical variables as numbers and percentages. For comparisons between groups, the independent sample Student t-test, or when appropriate, Mann-Whitney U test was used. The
Chi-square test or when appropriate, Fisher's exact test was used for the comparison of categorical variables. All statistical tests were two-sided, and a $p$-value $<0.05$ was considered significant. Statistical analysis was performed using the Statistical Package for the Social Sciences, version 22.0 for Windows ${ }^{\circledast}$ system (SPSS ${ }^{\circledast}$ Inc., Chicago, Illinois, USA).

\section{RESULTS}

\section{Study population and characteristics}

As illustrated in Figure 1, patients hospitalized for COVID-19 pneumonia were retrospectively evaluated and a total of 25 patients (13 in the steroid group and 12 in the control group) were included in the final analysis.

The mean age of the participants was significantly higher in the steroid group $(\mathrm{p}=0.005)$; however, there was no significant difference between the groups in terms of comorbidities, smoking habits, and COVID contact (Table I).

\section{Laboratory findings and disease severity scores}

Baseline (on admission) laboratory findings regarding the lymphocyte count and percentage, D-dimer, NT-proBNP, CRP, procalcitonin, ferritin, fibrinogen, and $\mathrm{LDH}$ were compared between the groups (Table II). There were significant differences at baseline in lymphocyte percentage $(9.8 \pm 3.2,7.0 \pm 2.9 ; \mathrm{p}=0.033)$ and D-dimer values (0.75 (0.60-1.43), 1.57 (0.91-2.29); $\mathrm{p}=0.047)$.

As shown in Table III, the lymphocyte percentage was higher in the steroid group when compared with the controls $(9.8 \pm 3.2$, $7.1 \pm 2.8 ; \mathrm{p}=0.033)$. There was no significant difference between the groups for the remaining laboratory parameters that were evaluated in the study protocol regarding the worst results during the hospitalization period.

Table I. Demographics and characteristics of participants $(n=25)$

\begin{tabular}{|c|c|c|c|}
\hline & $\begin{array}{l}\text { Steroid } \\
(+)\end{array}$ & $\begin{array}{c}\text { Steroid } \\
(-)\end{array}$ & p value \\
\hline \multicolumn{4}{|l|}{ Demographics } \\
\hline Age, years & $64.8 \pm 13.9$ & $48.3 \pm 12.8$ & 0.005 \\
\hline Male gender, $\%$ & 61.5 & 83.3 & 0.225 \\
\hline Current smoker, $\%$ & 15.4 & 41.7 & 0.144 \\
\hline COVID-19 (+) contact, $\%$ & 46.2 & 41.7 & 0.821 \\
\hline \multicolumn{4}{|l|}{ Comorbidities } \\
\hline Hypertension, \% & 30.8 & 41.7 & 0.571 \\
\hline Diabetes Mellitus, \% & 23.1 & 16.7 & 0.689 \\
\hline Hyperlipidemia, \% & 7.7 & 0.0 & 0.327 \\
\hline Thyroid function disorder, $\%$ & 7.7 & 8.3 & 0.953 \\
\hline Pulmonary disease, $\%$ & 15.4 & 25.0 & 0.548 \\
\hline Hepatic disease, $\%$ & 7.7 & 0.0 & 0.327 \\
\hline Cardiac disease, $\%$ & 0.0 & 16.7 & 0.125 \\
\hline Cancer, \% & 7.7 & 0.0 & 0.327 \\
\hline Chronic inflammatory disease, $\%$ & 15.4 & 0.0 & 0.157 \\
\hline
\end{tabular}


Table II. Baseline laboratory findings, radiological and clinical scores of the study population $(n=25)$

\begin{tabular}{|c|c|c|c|}
\hline & $\begin{array}{l}\text { Steroid } \\
(+)\end{array}$ & $\begin{array}{l}\text { Steroid } \\
(-)\end{array}$ & p value \\
\hline \multicolumn{4}{|l|}{ Laboratory } \\
\hline $\begin{array}{l}\text { Lymphocyte count, } x 10^{3} \\
/ \mu \mathrm{L}\end{array}$ & $1200 \pm 584.5$ & $1116.7 \pm 687.9$ & 0.747 \\
\hline Lymphocyte, \% & $20.4 \pm 10.6$ & $12.4 \pm 6.9$ & 0.038 \\
\hline D-dimer, mg/L (IQR) & $\begin{array}{c}0.75 \\
(0.60-1.43) \\
\end{array}$ & $\begin{array}{c}1.57 \\
(0.91-2.29) \\
\end{array}$ & 0.047 \\
\hline NT-proBNP, ng/L (IQR) & $\begin{array}{c}204.4 \\
(118.01-512.50) \\
\end{array}$ & $\begin{array}{c}510.0 \\
(204.0-2353.0) \\
\end{array}$ & 0.159 \\
\hline CRP, mg/L & $88.4 \pm 61.63$ & $126.8 \pm 72.3$ & 0.173 \\
\hline $\begin{array}{l}\text { Procalcitonin, } \mu \mathrm{g} / \mathrm{ml} \\
\text { (IQR) }\end{array}$ & $0.11(0.08-0.16)$ & $\begin{array}{c}0.18(0.11- \\
0.36)\end{array}$ & 0.056 \\
\hline Ferritin, $\mu \mathrm{g} / \mathrm{L}$ & $757.4 \pm 241.5$ & $555.4 \pm 334.5$ & 0.459 \\
\hline Fibrinogen, mg/dL & $537.9 \pm 213.0$ & $627.2 \pm 213.0$ & 0.242 \\
\hline $\mathrm{LDH}, \mathrm{U} / \mathrm{L}$ & $505.2 \pm 400.3$ & $544.0 \pm 211.5$ & 0.767 \\
\hline \multicolumn{4}{|c|}{ Radiological and Clinical Staging } \\
\hline CT scores & $12.5 \pm 3.9$ & $10.3 \pm 4.7$ & 0.199 \\
\hline WHO progression Scale & $5.8 \pm 1.3$ & $5.8 \pm 1.2$ & 0.990 \\
\hline
\end{tabular}

NT: $N$ terminal, BNP: brain natriuretic peptide, CRP: C-reactive protein, LDH: Lactate dehydrogenase, CT: computed tomography, WHO: World Health Organization

Table III. The worst laboratory findings during hospitalization, lengths of hospital stay and time needed for cessation of oxygen requirement $(n=25)$

\begin{tabular}{|c|c|c|c|}
\hline & $\begin{array}{l}\text { Steroid } \\
(+)\end{array}$ & $\begin{array}{c}\text { Steroid } \\
(-)\end{array}$ & p value \\
\hline \multicolumn{4}{|l|}{ Laboratory } \\
\hline Lymphocyte count, $\mathrm{x} 10^{3} / \mu \mathrm{L}$ & $807.7 \pm 213.9$ & $691.7 \pm 314.7$ & 0.289 \\
\hline Lymphocyte, \% & $9.8 \pm 3.2$ & $7.0 \pm 2.9$ & 0.033 \\
\hline D-dimer, mg/L (IQR) & $\begin{array}{c}1.78 \\
(1.26-3.49)\end{array}$ & $\begin{array}{c}1.56 \\
(0.85-4.93)\end{array}$ & 0.538 \\
\hline NT-proBNP, ng/L (IQR) & $\begin{array}{c}155 \\
(0-373) \\
\end{array}$ & $\begin{array}{c}375 \\
(155-1204) \\
\end{array}$ & 0.057 \\
\hline $\mathrm{CRP}, \mathrm{mg} / \mathrm{L}$ & $144.2 \pm 61.6$ & $182.8 \pm 56.5$ & 0.118 \\
\hline Procalcitonin, $\mu \mathrm{g} / \mathrm{ml}$ & $\begin{array}{c}0.24 \\
(0.14-7.66)\end{array}$ & $\begin{array}{c}0.29 \\
(0.13-0.56) \\
\end{array}$ & 0.807 \\
\hline Ferritin, $\mu \mathrm{g} / \mathrm{L}$ & $925.1 \pm 881.1$ & $839.9 \pm 398.0$ & 0.762 \\
\hline Fibrinogen, $\mu \mathrm{g} / \mathrm{dl}$ & $443.2 \pm 243.1$ & $415.4 \pm 155.3$ & 0.732 \\
\hline $\mathrm{LDH}, \mathrm{U} / \mathrm{L}$ & $583.5 \pm 374.1$ & $681.3 \pm 220.9$ & 0.425 \\
\hline \multicolumn{4}{|c|}{ Clinical staging and length of hospital stay } \\
\hline H-index $(\max )$ & $45.4 \pm 33.9$ & $41.5 \pm 19.3$ & 0.727 \\
\hline WHO progression scale (max) & $5.9 \pm 1.8$ & $6.1 \pm 0.9$ & 0.689 \\
\hline $\begin{array}{l}\text { Time needed for cessation of } \\
\text { oxygen need }\end{array}$ & $6.23 \pm 3.4$ & $7.67 \pm 2.1$ & 0.217 \\
\hline Total length of hospital stay & $18.5 \pm 7.8$ & $16.3 \pm 4.7$ & 0.406 \\
\hline
\end{tabular}

$N T$ : $N$ terminal, BNP: brain natriuretic peptide, CRP: C-reactive protein, LDH: Lactate dehydrogenase, CT: computed tomography, WHO: World Health Organization
Also, there was no significant difference between the groups regarding the disease severity indices such as the WHO progression scale and $\mathrm{H}$-index scores both at baseline and also considering the worst results during the hospitalization period. Most of the participants were in stage $2 \mathrm{~B}$ in both the steroid and non-steroid groups regarding the pneumonia indices upon admission (Figure 2).
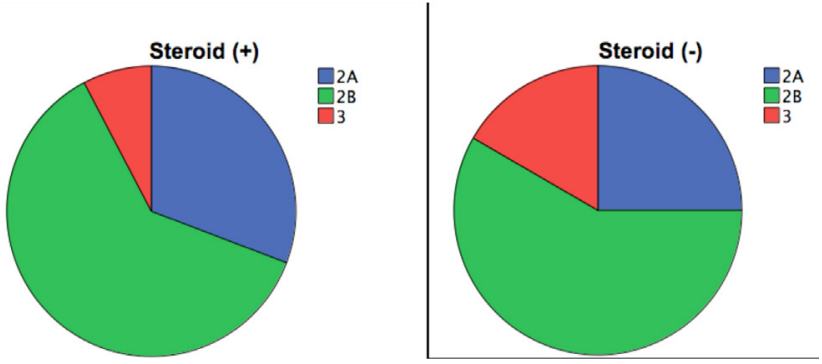

Figure 2: Pneumonia indices of patients on admission

2A: Pulmonary involvement without hypoxia

2B: Pulmonary involvement with hypoxia

3: Systemic hyperinflammation

\section{Treatment}

There were four different treatment modalities given to the participants. The hydroxychloroquine + azithromycin + favipiravir combination was preferred for $40 \%$ of the participants. Thirty-six percent were treated with hydroxychloroquine + azithromycin, $20 \%$ received hydroxychloroquine + favipiravir, and only one patient had hydroxychloroquine alone.

\section{Steroid treatment}

Methylprednisolone was started as a mean dose of 40-80 mg/day and the mean total steroid dose was $306 \pm 119.8 \mathrm{mg}$, while mean steroid treatment period was $6.38 \pm 3.6$ days.

When cut-off points were determined for both the steroid and non-steroid groups (while patients were considered as recovered from the acute period of disease but had oxygen requirement in the $7-10^{\text {th }}$ days of infection) regarding the duration till the cessation of oxygen support, it was observed that it took less time for the steroid group $(6.23 \pm 3.4$ vs. $7.67 \pm 2.1$ days, $p=0.217)$, but it was not statistically significant. Also, steroid treatment did not affect total length of hospital stay.

\section{DISCUSSION}

In this study, systemic steroid treatment initiated in the subacute period because of persisting oxygen requirement, despite 
standard COVID-19 treatment provided a tendency of decrease in time to cessation of oxygen supplementation.

Studies conducted to date about the use of systemic steroids in viral pneumonia (e.g. influenza, SARS) have shown that systemic steroids, particularly when used in the early period, have negative consequences on viral replication [21] and increase mortality $[11,22]$. However, a retrospective study in patients with SARS showed that steroids were initiated either as acute or rescue treatments reduced mortality and length of hospital stay [23].

It has been stated that in non-COVID-19 viral pneumonia that progresss to ARDS, systemic steroids have little or no effect on the length of stay in intensive care, but they may have positive effects on the need for mechanical ventilation and length of hospital stay, albeit with a low level of evidence. However, it was also emphasized that severe hyperglycemia due to steroids could be observed [24]. Considering all these data, the general belief prevents the use of systemic steroids as a standard treatment in the early period of viral pneumonia.

There are few studies on the use of systemic steroids in the treatment of COVID-19, and the results are confusing. In a study evaluating the risk factors of ARDS and mortality in patients with COVID-19, it was stated that the use of methylprednisolone in patients with ARDS might reduce the risk of death [25]. A metaanalysis reported a decrease in 28-day mortality for critically ill patients with COVID-19 who received steroids [26].

Unlike these studies, our patients had no ARDS and were administered steroids due to their ongoing requirement of oxygen supplementation despite the regression of COVID-19 pneumonia. A study conducted in Spain showed that pulse methylprednisolone treatment given to the patients with worsening respiratory function and increasing inflammatory markers in the second week of the disease had improved the prognosis [27]. Contrary to the study [28] showing that low-dose steroid therapy provides early clinical recovery, reduced length of stay in intensive care, and improvement in oxygenation, the $\mathrm{WHO}$ does not recommend routine use of steroids in the treatment of COVID-19 and only recommends its use in critically ill patients [29]. The basis of this approach was derived from reviews and meta-analyses that indicated increased mortality or ineffective results on mortality and length of hospital stay after steroid treatment [30-32]. A recent trial in Brazil also could not show the mortality benefit of methylprednisolone in hospitalized patients [33]. The patients included in our study comprised those who were passed the early period of infection. Considering the pathologic extent of the disease, a study evaluating post-mortem biopsies of patients who died of COVID-19 pneumonia found that acute fibrinous and organizing pneumonia findings were prominent, especially in the subacute period of the disease. This damage was seen to occur from an organizing pneumonia pattern characterized by intense intraalvelolar fibrin deposition and fibrinous acute injury in alveolar ducts and bronchioles, and fibroblasts surrounding intraalveolar fibrin were noted in almost all patients. The authors noted that the use of corticosteroids might be beneficial in treatment with these findings [34]. In another paper, a perspective, authors have taken into attention that, due to organizing pneumonia patterns in COVID-19, prolonged duration of corticosteroid treatment; and careful and monitored tapering should be kept in mind [35]. In our study, patients who had left the acute period marked by ongoing viral replication but had ongoing oxygen demand, there was a tendency of decreased duration until the need for oxygen disappeared in the steroid treatment group when compared with the controls. This may have been due to the limited number of patients enrolled in the study. The cause of the increased total length of stay of patients who were treated with steroids could be attributed to the time before steroid treatment. Furthermore, the development of hyperglycemia, muscle weakness, gastrointestinal bleeding, or secondary bacterial infection due to steroid use was not observed and steroid therapy was administered safely.

\section{Limitations}

The most important limitation of our study is its retrospective character and a low number of patients. However, we aimed to share the short-term results of patients treated with corticosteroids as the experience in the first period of the pandemic.

\section{Conclusion}

As a result, in patients whose viral replication phase was over but still had persisting chronic inflammation and oxygen requirement, the addition of systemic steroids to the standard treatment affects the time to discontinuation of oxygen supplementation in a positive way. It was also observed that, in terms of adverse effects, low-medium dose steroid treatment was safe for these patients who are mostly old with comorbid medical conditions. To determine the role of steroids in the treatment protocols, randomized controlled studies with a large number of patients are needed.

\section{Compliance with Ethical Standards}

Ethical approval: The permission for the study was obtained from the Ministry of Health of the Republic of Turkey on May $10^{\text {th }}, 2020$, and the ethical approval was obtained from the Marmara University, School of Medicine Clinical Research Ethics Committee (approval number: 09.2020.561).

Financial Disclosure: The authors declared that this study has received no financial support.

Conflict of Interest: The authors have no conflicts of interest to declare.

Authors' Contributions: Conception-design, data collection, writing and critical revision: DK, Conception-design, writing and critical revision: SOY, Conception-design, data analysis, writing: $\mathrm{BB}$, Conception-design, critical revision: $\mathrm{EE}$, Conception-design, critical revision 


\section{REFERENCES}

[1] Zhou F, Yu T, Du R, et al. Clinical course and risk factors for mortality of adult inpatients with COVID-19 in Wuhan, China: a retrospective cohort study. Lancet 2020;395(10229):1054-62. doi: 10.1016/S0140-6736(20)30566-3

[2] Cheng ZJ, Shan J. 2019 Novel coronavirus: where we are and what we know. Infection 2020;48:155-63. doi: 10.1007/ s15010.020.01401-y

[3] Novel Coronavirus Pneumonia Emergency Response Epidemiology Team - The Epidemiological Characteristics of an Outbreak of 2019 Novel Coronavirus Diseases (COVID-19) Available at: http://weekly.chinacdc.cn/en/ article/id/e53946e2-c6c4-41e9-9a9b-fea8db1a8f51. Accessed: 08.01 .2021

[4] Xu Z, Shi L, Wang Y, et al. Pathological findings of COVID-19 associated with acute respiratory distress syndrome. The Lancet Respiratory Medicine 2020;8:420-2. doi: 10.1016/ S2213-2600(20)30076-X

[5] Gattinoni L, Coppola S, Cressoni M, Busana M, Rossi S, Chiumello D. COVID-19 does not lead to a "Typical" acute respiratory distress syndrome. Am J Respir Crit Care Med 2020;201:1299-300. doi: 10.1164/rccm.202.003.0817LE

[6] Klok FA, Kruip M, van der Meer NJM, et al. Confirmation of the high cumulative incidence of thrombotic complications in critically ill ICU patients with COVID-19: An updated analysis. Thromb Res 2020;191:148-50. doi: 10.1016/j. thromres.2020.04.041

[7] Mehta N, Mazer-Amirshahi M, Alkindi N, Pourmand A. Pharmacotherapy in COVID-19; A narrative review for emergency providers. Am J Emerg Med 2020;38:1488-93. doi: 10.1016/j.ajem.2020.04.035

[8] Jiang S, Liu T, Hu Y, et al. Efficacy and safety of glucocorticoids in the treatment of severe community-acquired pneumonia: A meta-analysis. Medicine 2019;98:e16239. doi: 10.1097/ MD.000.000.0000016239

[9] Arabi YM, Mandourah Y, Al-Hameed F, et al. Corticosteroid therapy for critically ill patients with middle east respiratory syndrome. Am J Respir Crit Care Med 2018;197:757-67. doi: 10.1164/rccm.201.706.1172OC

[10] Stockman LJ, Bellamy R, Garner P. SARS: systematic review of treatment effects. PLoS Medicine 2006;3:e343. doi: 10.1371/ journal.pmed.0030343

[11] Moreno G, Rodriguez A, Reyes LF, et al. Corticosteroid treatment in critically ill patients with severe influenza pneumonia: a propensity score matching study. Intensive Care Med 2018;44:1470-82. doi: 10.1007/s00134.018.5332-4

[12] Marik PE. Steroids for sepsis: yes, no or maybe. J Thorac Dis 2018;10(Suppl 9):S1070-S3. doi: 10.21037/jtd.2018.04.35

[13] Biffl WL, Moore FA, Moore EE, Haenel JB, McIntyre RC, Jr., Burch JM. Are corticosteroids salvage therapy for refractory acute respiratory distress syndrome? Am J Surg 1995;170:5915; discussion 5-6. doi: 10.1016/s0002-9610(99)80022-1

[14] Zhou W, Liu Y, Tian D, et al. Potential benefits of precise corticosteroids therapy for severe 2019-nCoV pneumonia.
Signal Transduct Target Ther 2020;5:18. doi: 10.1038/ s41392.020.0127-9

[15] RECOVERY Collaborative Group, Horby P, Lim WS, Emberson JR, et al. Dexamethasone in hospitalized patients with Covid-19 - Preliminary report. N Engl J Med 2021;384:963-704. doi: 10.1056/NEJMoa2021436

[16] Republic of Turkey, Ministry of Health April 14th 2020 Available at: https://covid19bilgi.saglik.gov.tr/tr/covid-19rehberi.html. Accessed 23.12.2020

[17] WHO Working Group on the Clinical Characterisation Management of COVID infection. A minimal common outcome measure set for COVID-19 clinical research. The Lancet Infect Dis 2020;20:e192-e7. doi: 10.1016/S14733099(20)30483-7

[18] Siddiqi HK, Mehra MR. COVID-19 illness in native and immunosuppressed states: A clinical-therapeutic staging proposal. J Heart Lung Transplant 2020;39:405-7. doi: 10.1016/j.healun.2020.03.012

[19] Li K, Fang Y, Li W, et al. CT image visual quantitative evaluation and clinical classification of coronavirus disease (COVID-19). Eur Radiol 2020;30:4407-16. doi: 10.1007/s00330.020.06817-6

[20] Mehta P, McAuley DF, Brown M, et al. COVID-19: consider cytokine storm syndromes and immunosuppression. Lancet 2020;395(10229):1033-4. doi: 10.1016/S01406736(20)30628-0

[21] Lee N, Allen Chan KC, Hui DS, et al. Effects of early corticosteroid treatment on plasma SARS-associated Coronavirus RNA concentrations in adult patients. J Clin Virol 2004;31:304-9. doi: 10.1016/j.jcv.2004.07.006

[22] Rodrigo C, Leonardi-Bee J, Nguyen-Van-Tam J, Lim WS. Corticosteroids as adjunctive therapy in the treatment of influenza. The Cochrane Database of Systematic Reviews 2016;3:CD010406. doi: 10.1002/14651858.CD010406.pub2

[23] Chen RC, Tang XP, Tan SY, et al. Treatment of severe acute respiratory syndrome with glucosteroids: the Guangzhou experience. Chest 2006;129:1441-52. doi: 10.1378/ chest.129.6.1441

[24] Ye Z, Wang Y, Colunga-Lozano LE, et al. Efficacy and safety of corticosteroids in COVID-19 based on evidence for COVID-19, other coronavirus infections, influenza, community-acquired pneumonia and acute respiratory distress syndrome: a systematic review and meta-analysis. CMAJ ( Canadian Medical Association Journal) 2020;192:E756-67. doi: 10.1503/cmaj.200645

[25] Wu C, Chen X, Cai Y, et al. Risk factors associated with acute respiratory distress syndrome and death in patients with coronavirus disease 2019 pneumonia in Wuhan, China. JAMA Intern Med 2020;180:934-43. doi: 10.1001/ jamainternmed.2020.0994

[26] WHO Rapid Evidence Appraisal for COVID-19 Therapies Working Group, Sterne JAC, Murthy S, Diaz JV, et al. Association Between Administration of Systemic Corticosteroids and Mortality Among Critically Ill Patients With COVID-19: A Meta-analysis. JAMA 2020;324:1330-41. doi: 10.1001/jama.2020.17023 
[27] Ruiz-Irastorza G, Pijoan JI, Bereciartua E, Dunder S, Dominguez J, Garcia-Escudero P, et al. Second week methylprednisolone pulses improve prognosis in patients with severe coronavirus disease 2019 pneumonia: An observational comparative study using routine care data. PLoS One 2020;15:e0239401. doi: 10.1371/journal.pone.0239401

[28] Wang Y, Jiang W, He Q, Wang C, Wang B, Zhou P, et al. Early, low-dose and short-term application of corticosteroid treatment in patients with severe COVID-19 pneumonia: single-center experience from Wuhan, China. medRxiv. 2020:2020.03.06.20032342. doi: 10.1101/2020.03.06.20032342

[29] WHO Living Guidance. Corticosteroids for COVID-19 2020 Available at :https://apps.who.int/iris/rest/bitstreams/1299344/ retrieve. Accessed: 17.12.2020

[30] Yang Z, Liu J, Zhou Y, Zhao X, Zhao Q, Liu J. The effect of corticosteroid treatment on patients with coronavirus infection: a systematic review and meta-analysis. J Infect 2020;81:e13-e20. doi: 10.1016/j.jinf.2020.03.062

[31] $\mathrm{Li} \mathrm{H}$, Chen $\mathrm{C}, \mathrm{Hu} \mathrm{F}$, et al. Impact of corticosteroid therapy on outcomes of persons with SARS-CoV-2,
SARS-CoV, or MERS-CoV infection: a systematic review and meta-analysis. Leukemia 2020;34:1503-11. doi: $10.1038 / \mathrm{s} 41375.020 .0848-3$

[32] Sarkar S, Khanna P, Soni KD. Are the steroids a blanket solution for COVID-19? A systematic review and metaanalysis. J Med Virol 2021;93:1538-47. doi: 10.1002/jmv.26483

[33] Jeronimo CMP, Farias MEL, Val FFA, et al. Methylprednisolone as adjunctive therapy for patients hospitalized with COVID-19 (Metcovid): A randomised, double-blind, phase iib, placebocontrolled trial. Clin Infect Dis 2021;72:e373-e81. doi: 10.1093/cid/ciaa1177

[34] Copin MC, Parmentier E, Duburcq T, et al. Time to consider histologic pattern of lung injury to treat critically ill patients with COVID-19 infection. Intensive Care Med 2020;46:11246. doi: 10.1007/s00134.020.06057-8

[35] Kory P, Kanne JP. SARS-CoV-2 organising pneumonia: 'Has there been a widespread failure to identify and treat this prevalent condition in COVID-19?'. BMJ Open Respir Res 2020;7:e000724. doi: 10.1136/bmjresp-2020-000724 